\section{Commentary: Can we predict late coronary events after arterial switch operation? A question without a simple answer}

\author{
Viktor Hraska, MD, $\mathrm{PhD},{ }^{\mathrm{a}}$ and \\ Benjamin H. Goot, MD $^{\mathrm{b}}$
}

Batteux and colleagues ${ }^{1}$ deserve our admiration and respect for their effort to address the oft-debated issue regarding how to identify patients at risk of coronary events following the arterial switch operation (ASO). These unique data reflect an 18-year experience at a single, busy institution known for excellent results and comprehensive follow-up.

The authors reviewed 100 randomly selected computed tomography (CT) scans from those patients free from coronary events after ASO and $21 \mathrm{CT}$ scans from patients who experienced a coronary event more than 3 years after ASO. Using 3-dimensional coronary modeling software, they found 4 left coronary artery (LCA) features associated with late coronary events. The authors provide a very thoughtful and tempered discussion of their data, concluding that imaging of coronary arteries after ASO might be useful to select patients at higher risk, thereby tailoring surveillance. From a surgical point of view, the essential question is whether these geometric findings can be translated into surgical techniques that minimize the risk of late coronary events.

A fair amount of experience has been attained regarding coronary transfer in all types of coronary patterns. Often these early experiences were painful. As Oscar Wilde said: "Experience is simply the name we give our mistakes." 2 The site of coronary reimplantation is most often

\footnotetext{
From the ${ }^{a}$ Division of Congenital Heart Surgery, Department of Surgery, and ${ }^{\mathrm{b}}$ Division of Cardiology, Department of Pediatrics, Herma Heart Institute, Medical College of Wisconsin, Milwaukee, Wis.

Disclosures: The authors reported no conflicts of interest.

The Journal policy requires editors and reviewers to disclose conflicts of interest and to decline handling or reviewing manuscripts for which they may have a conflict of interest. The editors and reviewers of this article have no conflicts of interest.

Received for publication June 24, 2020; revisions received June 24, 2020; accepted for publication June 24, 2020; available ahead of print July 11, 2020.

Address for reprints: Viktor Hraska, MD, PhD, Division of Congenital Heart Surgery, Department of Surgery, Herma Heart Institute, Medical College of Wisconsin,

9000 W Wisconsin Ave, B730, Milwaukee, WI 53226 (E-mail: vhraska@ chw.org). J Thorac Cardiovasc Surg 2021;161:1405-6

$0022-5223 / \$ 36.00$

Copyright (C) 2020 by The American Association for Thoracic Surgery

https://doi.org/10.1016/j.jtcvs.2020.06.086
}

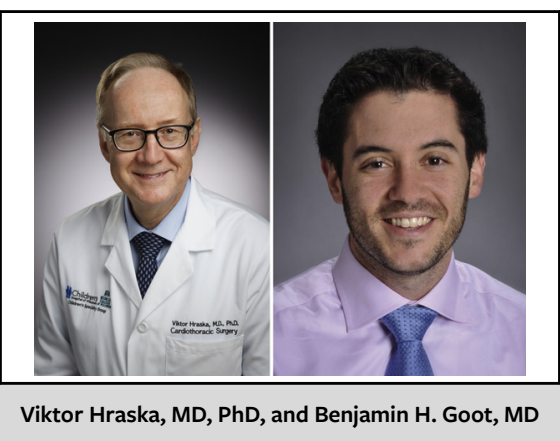

CENTRAL MESSAGE

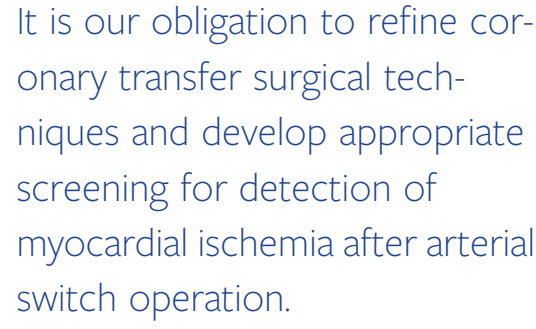

dictated by the anatomic situation more than it is chosen. Nevertheless, based on our experiences, there has been a tendency to avoid medial implantation of coronaries whenever it is possible. Therefore both coronaries should be implanted more laterally, with the LCA at a moderate height in the sinus, so that the takeoff may achieve a less-acute angle and avoid the pulmonary trunk. This practice is consistent with the CT-based LCA geometric findings identified in this study. It is also noteworthy that similar high-risk geometric parameters of the right coronary artery were not identified, which undermines the validity of this method. Lastly, the events themselves are so rare, more data are certainly needed to improve the methodology.

Another relevant question is whether it is justifiable to use screening CT imaging routinely for all patients after ASO. At this point, this is very unlikely. The limited number of events alone, at least during the first 3 decades after ASO, would argue against routine screening to detect asymptomatic coronary obstruction. ${ }^{3}$ Secondly the proposed method is time- and effort-consuming, and exposes patients to radiation. Although spatial resolution provided by $\mathrm{CT}$ is sacrificed, utilizing cardiac magnetic resonance imaging with stress perfusion can provide useful coronary artery imaging in addition to quantification of ventricular function, tissue characterization, and myocardial perfusion data. ${ }^{4,5}$ These data are also important when assessing for evidence of ischemia, particularly in patients who had medially implanted coronaries. Regardless, we agree with the authors that coronary events after ASO are not normal and in the 
future more appropriate targeted screening of some kind should occur.

We commend Batteux and colleagues ${ }^{1}$ for their important contribution in developing more objective follow up protocols after ASO.

\section{References}

1. Batteux C, Abakka S, Gaudin R, Vouhé P, Raisky O, Bonnet D. Three-dimensional geometry of coronary arteries after arterial switch operation for transposition of the great arteries and late coronary events. J Thorac Cardiovasc Surg. 2021; 161:1396-404.
2. Wilde O. Experience is simply the name we give our mistakes. Available at: https://www.brainyquote.com/quotes/oscar_wilde_105029. Accessed July 12, 2020 .

3. van Wijk SWH, van der Stelt F, Ter Heide H, Schoof PH, Doevendans PAFM, Meijboom FJ, et al. Sudden death due to coronary artery lesions long-term after the arterial switch operation: a systematic review. Can J Cardiol. 2017:33:1180-7.

4. Noel CV, Krishnamurthy R, Masand P, Moffett B, Schlingmann T, Cheong BY, et al. Myocardial stress perfusion MRI: experience in pediatric and young-adult patients following arterial switch operation utilizing regadenoson. Pediatr Cardiol. 2018;39:1249-57.

5. Tobler D, Motwani M, Wald RM, Roche SL, Verocai F, Iwanochko RM, et al. Evaluation of a comprehensive cardiovascular magnetic resonance protocol in young adults late after the arterial switch operation for d-transposition of the great arteries. J Cardiovasc Magn Reson. 2014;16:98.
See Article page 1396.

\section{Commentary: Coronary origins after the arterial switch operation: Let's think of it like anomalous aortic origin of the coronaries}

\author{
Charles D. Fraser, Jr, MD
}

We have gotten really good at moving coronary ostia. The hallmark of a successful arterial switch operation (ASO) is accurate translocation of the coronary ostia, no matter how they originate, to what becomes the aortic root ("neo-aortic root"). Congenital heart surgeons have developed many effective techniques to perform the ASO in essentially every coronary branching pattern and ostial orientation. Furthermore, we have ways to deal with an intramural course of a main coronary artery, a single coronary ostium, and all varieties of great vessel orientation. Thus, expectations for survival after the ASO are very high, and

\footnotetext{
From the Texas Center for Pediatric and Congenital Heart Disease, The University of Texas - Dell Medical School, Dell Children's Hospital, Austin, Tex.

Disclosures: The author reported no conflicts of interest.

The Journal policy requires editors and reviewers to disclose conflicts of interest and to decline handling or reviewing manuscripts for which they may have a conflict of interest. The editors and reviewers of this article have no conflicts of interest.

Received for publication July 2, 2020; revisions received July 2, 2020; accepted for publication July 2, 2020; available ahead of print July 13, 2020.

Address for reprints: Charles D. Fraser, Jr, MD, Texas Center for Pediatric and Congenital Heart Disease, Dell Children's Hospital, 4900 Mueller Blvd, Austin, TX 78723 (E-mail: Charles.fraser@austin.utexas.edu).

J Thorac Cardiovasc Surg 2021;161:1406-7 0022-5223/\$36.00

Copyright $₫ 2020$ Published by Elsevier Inc. on behalf of The American Association for Thoracic Surgery

https://doi.org/10.1016/j.jtcvs.2020.07.020
}

Check for updates

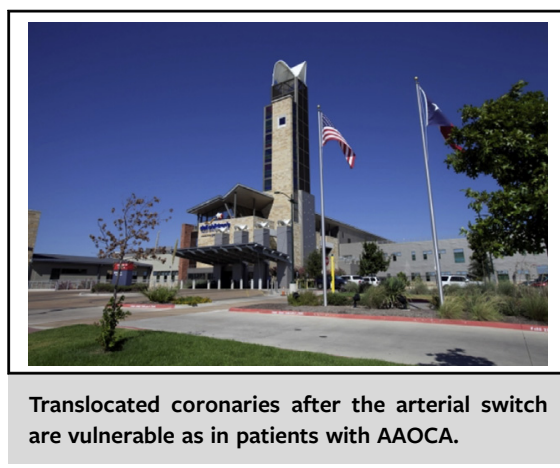

CENTRAL MESSAGE

The translocated coronary ostia and main coronary arteries after

the arterial switch operation

should be thought of as we do in

patients with anomalous aortic

origin of a coronary artery.

they should be. As we have reported recently, in a series of 394 patients (including transposition of the great arteries with intact ventricular septum, transposition of the great arteries with ventricular septal defect with/without aortic arch hypoplasia, and the Taussig-Bing anomaly [doubleoutlet right ventricle with subpulmonary ventricular septal defect]), we had no in-hospital deaths and 1 out-ofhospital death over the last 23 years. ${ }^{1}$ Others have achieved similar results.

Short- and intermediate-term outcomes, however, do not tell the whole story. Information continues to accrue concerning the fate of translocated coronary ostia and coronary arteries after the ASO. Some ostia and proximal coronaries do occlude or become stenotic. Thus, we are left with 